\title{
Effect of coating operating parameters on electrode physical characteristics and final electrochemical performance of lithium-ion batteries
}

\author{
L. A. Román-Ramírez ${ }^{1,2,3}$ (1) G. Apachitei ${ }^{1,3} \cdot$ M. Faraji-Niri ${ }^{1,3} \cdot$ M. Lain ${ }^{1,3} \cdot$ D. Widanage ${ }^{1,3} \cdot$ J. Marco ${ }^{1,3}$
}

Received: 22 September 2021 / Accepted: 4 February 2022 / Published online: 4 March 2022

(c) The Author(s) 2022

\begin{abstract}
The effect of coating parameters of NMC622 cathodes and graphite anodes on their physical structure and half-cell electrochemical performance is evaluated by design of experiments. Coating parameters include the coater comma bar gap, coating ratio and web speed. The electrochemical properties studied are gravimetric and volumetric capacity, rate performance, areal specific impedance (ASI) and C-rate. Differences in the manufacturing effects on the electrode physical structure and electrochemical performance are observed between the electrodes and are modelled by linear regression. The effect of cell coating weight and porosity on half-coin cell electrochemical performance is also evaluated by linear regression. The cathode performance at high gravimetric and volumetric C-rates is mainly influenced by coating weight, whereas porosity is the only explanatory variable for volumetric $\mathrm{C}$-rates of $1 \mathrm{C}$ and below. For anode, correlations are only found for the $\mathrm{C} / 20$ and $5 \mathrm{C}$ gravimetric and volumetric capacities and are related to coating weight. An inverse relationship between ASI and coating weight is observed for cathode, but in general the cell physical characteristics cannot completely explain the observed ASI for both electrodes. The obtained models are useful for the design and robust manufacturing of electrodes since present a quantitative relationship between the coating parameters, cell characteristics and final cell electrochemical performance.
\end{abstract}

Keyword Lithium-ion batteries $\cdot$ Electrode coating $\cdot$ Design of experiments $\cdot$ Capacity $\cdot$ Areal specific impedance $\cdot$ Anode $\cdot$ Cathode

\section{Introduction}

Lithium-ion batteries (LIBs) are currently the main technology underpinning the development of electric vehicles (EVs) due to their higher power density, higher gravimetric and volumetric energy and longer service life compared with other secondary batteries [1,2]. Still, the market share of EVs is just a fraction of the whole market still dominated by internal combustion vehicles [3]. To increase the uptake of EVs by a wider population, the cost of the battery pack,

L. A. Román-Ramírez

romanral@1sbu.sc.uk

1 Warwick Manufacturing Group, University of Warwick, Coventry CV4 7AL, UK

2 London South Bank University, 103 Borough Road, London SE1 0AA, UK

3 The Faraday Institution, Harwell Science and Innovation Campus, Quad One, Didcot, UK the most expensive component in an $\mathrm{EV}$, has to decrease considerably from its current estimated price of $\$ 200$ per $\mathrm{kWh}$ [4]. LIBs' manufacturing costs can be substantially lessened by a proper understanding of the effect of process parameters on electrode physical structure and ultimately on the cell electrochemical performance $[5,6]$. However, such an understanding is challenging due to the complex LIB's manufacturing chain involving several subprocesses (slurry preparation, coating, drying, calendering, cell assembly and testing) [7-9] and hundreds of process variables [6]. Some of the process variables may have an immediate effect on intermediate product properties, but some may only influence the final product. Knowledge of the effect of the key cell physical characteristics on the cell electrochemical performance is important from the design point of view. From the manufacturing perspective, the determination of the key operating variables and the link to the key cell physical characteristics is arguably more important.

A few works can be found in the literature directed at understanding the effect of manufacturing operating 
parameters on intermediate products or final cell performance by different techniques [8, 10-19]. Mixing operating parameters such as mixing sequence and mixing temperature and their effect on cycling stability and C-rate performance have been reported by some authors [10-12, 17]. Calendering parameters such as pressure, roll temperature and electrode composition and their influence on electrode mechanical and electrochemical properties have been researched by different groups $[8,13,14]$. The cathode coating-drying process was studied by Román-Ramírez et al. [15] by a screening design of experiments (DoE) method to identify and model the relationship between the critical process variables and cell electrochemical performance. The models obtained, however, were restricted to linear models since the experimental design chosen, the Plackett-Burman design, was only aimed at identifying main effects [15].

In the present paper, the previously identified main coating-drying process parameters for cathode in [15] are studied further by a response surface methodology (RSM) approach. Additionally, the anode coating-drying parameters are also studied. RSM is a statistical tool used for model development and optimisation by evaluating simultaneous changes in several independent variables (factors) and their influence on a dependent variable or response [20]. To the best of the author's knowledge, this is the first application of an RSM design to the study of the LIB's coating manufacturing step. The first objective of the study is to quantify the effects of manufacturing conditions on the electrodes' and cell's physical characteristics and their electrochemical performance and to determine potential optimum settings. The physical characteristics studied are: mass loadings dry and wet, pre-calendered and calendered thickness, pre-calendered and calendered porosity, cell thickness, cell coating weight and cell porosity. A second objective is to analyse the effect of cell physical characteristics (thickness, coating weight and porosity) on cell electrochemical performance. Performance measurements include the gravimetric capacity, volumetric capacity, rate performance and areal specific impedance (ASI).

\section{Materials and methods}

\section{Design of experiments}

Based on the previous results reported by Román-Ramírez, et al. [15, 21], an inscribed central composite design (ICCD) was chosen in the present study as part of the RSM. In a $\mathrm{CCD}$, each factor contains 5 settings or levels, belonging to axial points, factorial points and the centre points [20]. A generic plot of the experimental points distribution for an ICCD for two factors is shown in Figure S1 in the supporting information.
The relationship between the $k$ number of factors $\left(x_{i}\right)$ and the response $(y)$ was expressed by a second-order polynomial of the form shown in Eq. (1).

$y^{\lambda}=\beta_{0}+\sum_{i=1}^{k} \beta_{i} x_{i}+\sum_{i=1}^{k-1} \sum_{j=i+1}^{k} \beta_{i j} x_{i} x_{j}+\sum_{i=1}^{k} \beta_{i i} x_{i}^{2}+\varepsilon$

The first term in Eq. (1) is the intercept, the second term corresponds to the main effects contributions, the third term denotes two-way factor interactions, and the fourth term are the quadratic contributions. The $\beta \mathrm{s}$ in Eq. (1) are the model coefficients estimated from linear regression [22], $\varepsilon$ is the random error, and $\lambda$ is a transformation parameter required for normalising a non-normal distribution [23]. The regression analysis was done considering coded factors, i.e. the factors' ranges were rescaled to +1 and -1 .

Non-statistically significant terms in Eq. (1) were removed according to a p-value criterion of 0.1 . Model fit statistics included the coefficient of multiple determination $\left(R^{2}\right)$, the adjusted $R^{2}\left(R_{a d j}^{2}\right)$ and the predicted $R^{2}\left(R_{p r e d}^{2}\right)$.

\section{Materials}

The cathode formulation for electrode manufacture consisted of $96 \mathrm{wt} \% \mathrm{LiNi}_{0.6} \mathrm{Mn}_{0.2} \mathrm{Co}_{0.2} \mathrm{O}_{2}$ (NMC622, BASF) active material (AM), $2 \mathrm{wt} \% \mathrm{C} 65$ (Imerys) conductive additive (CA) and $2 \mathrm{wt} \%$ polyvinylidene difluoride (PVDF 5130, Solvay) as binder (B). 1-methyl-2-pyrrolidinone (NMP, ACROS Organics) was used as the solvent.

The anode formulation consisted of $95.25 \mathrm{wt} \%$ S360-E3 graphite (BTR) AM, $1 \mathrm{wt} \%$ C45 (Imerys) CA, $1.5 \mathrm{wt} \%$ BVH8 CMC (Ashland) as binder 1, and $2.25 \mathrm{wt} \%$ BM-451B SBR (Zeon) as binder 2. Deionised water was used as the solvent.

\section{Electrode and coin cell manufacture}

\section{Mixing}

For each electrode, the corresponding solid components were initially dry mixed followed by a kneading process in a $1 \mathrm{~L}$ intensive mixer (EL1, Eirich). A fraction of the solvent was added to the mix, and the components were continuously stirred until reaching an assumed homogeneous slurry. The rest of the corresponding solvent was added in the dilution stage to reach solid contents of $66.5 \%$ and $46.3 \%$ for cathode and anode, respectively. For both electrodes, the rotor speeds were set to $15 \mathrm{~m} / \mathrm{s}$ during the dry mixing and to $10 \mathrm{~m} / \mathrm{s}$ during the kneading stage. The mixing pan speeds were kept constant at $0.7 \mathrm{~m} / \mathrm{s}$. The slurries were then degassed to remove any bubbles formed during the mixing stage. 


\section{Coating and drying}

Coating and drying took place in a pilot-plant Megtec Systems convective coater conformed of three drying zones. Details about the equipment configuration and its operation can be found in a previous publication [15].

The studied parameters and ranges of the cathode coating and drying process were comma bar gap $(80 \mu \mathrm{m}-140 \mu \mathrm{m})$, web speed $(0.5 \mathrm{~m} / \mathrm{min}-1.5 \mathrm{~m} / \mathrm{min})$ and coating ratio (110\%-150\%). The set of experiments (design matrix) given by the ICCD after randomisation are shown in Table 1 . The design considers 8 factorial points, 6 centre points and 6 axial points. Air speed and drying temperature have been identified as parameters not significantly affecting cathode performance under a certain range of conditions stated in [15] and were thus kept constant in the present work. Air speed was set to $15 \mathrm{~m} / \mathrm{s}$, whereas the three oven drying sections were kept at $85{ }^{\circ} \mathrm{C}, 110{ }^{\circ} \mathrm{C}$ and $95{ }^{\circ} \mathrm{C}$, respectively. The cathode slurries were coated onto a $15-\mu \mathrm{m}$ thickness aluminium foil current collector.

For the anode, the studied parameters and ranges were comma bar gap $(100 \mu \mathrm{m}-190 \mu \mathrm{m})$ and coating ratio (100\%-150\%). Preliminary experimental work showed that web speed, air speed and drying temperature were not statistically significant factors. The design matrix for anode is shown in Table 1 . The design considers 4 factorial points,
5 centre points and 4 axial points. The web speed was set to $1 \mathrm{~m} / \mathrm{min}$, air speed to $15 \mathrm{~m} / \mathrm{s}$, whereas the three oven drying sections at $45^{\circ} \mathrm{C}, 60^{\circ} \mathrm{C}$ and $60{ }^{\circ} \mathrm{C}$, respectively. The anode slurries were coated onto a $10-\mu \mathrm{m}$-thickness copper foil current collector.

The electrodes were cut into strips and were placed in a vacuum oven at $120{ }^{\circ} \mathrm{C}$ for $12 \mathrm{~h}$ to ensure the complete removal of the solvents.

\section{Calendering and cutting}

The dried electrodes were calendered in a small research and development calendered (Innovative Machine Corporation) at $0.5 \mathrm{~m} / \mathrm{s}$ line speed. The rolls were heated to $85{ }^{\circ} \mathrm{C}$ for cathode, whereas for anode they were kept at room temperature. The targeted calendered porosity was $30 \%$ for both electrodes; however, since the calendering was done on $9 \mathrm{~cm} \times 15 \mathrm{~cm}$ sheets using the average thickness and coating weight values with the target porosity at the local level where the coin cells were cut, the final porosities ranged from 33.93 to 37.67 for anode and 28.63 and 32.48 for cathode.

Cathode discs of $14.8 \mathrm{~mm}$ diameter and anode discs of $15 \mathrm{~mm}$ were punched by EL-Cell electrode cutters for coin cell fabrication.
Table 1 Experimental design matrices for cathode and anode according to the inscribed central composite design

\begin{tabular}{|c|c|c|c|c|c|c|}
\hline \multicolumn{4}{|l|}{ Cathode } & \multicolumn{3}{|l|}{ Anode } \\
\hline Experiment & $\begin{array}{l}\text { Comma bar } \\
\operatorname{gap}(\mu \mathrm{m})\end{array}$ & $\begin{array}{l}\text { Coating } \\
\text { ratio }(\%)\end{array}$ & $\begin{array}{l}\text { Web speed } \\
(\mathrm{m} / \mathrm{min})\end{array}$ & Experiment & $\begin{array}{l}\text { Comma bar } \\
\text { gap }(\mu \mathrm{m})\end{array}$ & $\begin{array}{l}\text { Coating } \\
\text { ratio } \\
(\%)\end{array}$ \\
\hline 1 & 128 & 142 & 0.7 & 1 & 145 & 130 \\
\hline 2 & 110 & 130 & 1.0 & 2 & 145 & 150 \\
\hline 3 & 80 & 130 & 1.0 & 3 & 113 & 144 \\
\hline 4 & 110 & 130 & 1.5 & 4 & 145 & 110 \\
\hline 5 & 110 & 110 & 1.0 & 5 & 145 & 130 \\
\hline 6 & 128 & 118 & 0.7 & 6 & 190 & 130 \\
\hline 7 & 92 & 142 & 1.3 & 7 & 145 & 130 \\
\hline 8 & 92 & 142 & 0.7 & 8 & 177 & 116 \\
\hline 9 & 110 & 130 & 1.0 & 9 & 113 & 116 \\
\hline 10 & 92 & 118 & 0.7 & 10 & 145 & 130 \\
\hline 11 & 110 & 130 & 1.0 & 11 & 177 & 144 \\
\hline 12 & 140 & 130 & 1.0 & 12 & 145 & 130 \\
\hline 13 & 110 & 130 & 1.0 & 13 & 100 & 130 \\
\hline 14 & 92 & 118 & 1.3 & & & \\
\hline 15 & 110 & 150 & 1.0 & & & \\
\hline 16 & 110 & 130 & 1.0 & & & \\
\hline 17 & 128 & 118 & 1.3 & & & \\
\hline 18 & 110 & 130 & 0.5 & & & \\
\hline 19 & 128 & 142 & 1.3 & & & \\
\hline 20 & 110 & 130 & 1.0 & & & \\
\hline
\end{tabular}




\section{Half-coin cell assembly}

To study the electrochemical performance of the cathode and anode electrodes separately, the electrodes were investigated in anode half-cells and cathode half-cells. Three coin cells were fabricated for each of the experimental conditions given in Table 1.

Coin cell assembly was carried out in a glove box under argon atmosphere with less than $0.5 \mathrm{ppm}$ of oxygen and water. 2032-type coin cell half cells were fabricated with single-sided coated electrodes discs. Lithium discs were used as the counter electrodes. A polypropylene/polyethylene/polypropylene microporous trilayer membrane (H1609, Celgard) was used as the separator. The anode half cells also contained a layer of glass fibre separator (GF/A), to improve the uniformity of the current distribution. The coin cells included a wave spring and 1-mm-thick stainless-steel spacer, for adequate pressure and sealing.

The cathode cells were filled with $60 \mu \mathrm{l}$ of RD281 electrolyte (1 $\mathrm{M} \mathrm{LiPF}_{6}$ in ethylene carbonate/ethyl methyl carbonate $(\mathrm{EC} / \mathrm{EMC})=3: 7(\mathrm{v} / \mathrm{v})+1 \mathrm{wt} \%$ vinylene carbonate (VC), SoulBrain). The anode cells were filled with $60 \mu \mathrm{l}$ of a lower viscosity electrolyte (1 M LiFSI in ethylene carbonate/dimethyl carbonate $(\mathrm{EC} / \mathrm{DMC})=1: 9(\mathrm{v} / \mathrm{v})+1 \mathrm{wt} \% \mathrm{LiPF}_{6}$, Solvionics).

\section{Characterisations}

\section{Electrode physical measurements}

Pre-calendered and calendered electrode thicknesses were determined by a digital thickness gauge (Mitutoyo) with a $1 \mu \mathrm{m}$ precision. The values are the mean of 10 measurements taken on different locations on a $9 \mathrm{~cm} \times 15 \mathrm{~cm}$ electrode strip. The thickness of the electrode discs used in the coin assembly was also measured by the digital gauge. The mass of the electrode discs was measured in a digital balance (Sartorius). The reported values of the cell thickness and mass are the mean of three coin cells. The mean values and standard deviations of the measurements taken on the strips and the coin cells can be found in the Online resource.

Mass loadings wet and dry were recorded by the scanning MeSys Systems machine. The data were processed as described in a previous communication [21]. The final values of the mass loadings and their standard deviations can be found in the Online resource.

The pre-calendered, calendered and cell porosities were computed from the thicknesses according to Eq. (2), where $P(\%)$ is the porosity, $\rho_{c t}\left(\mathrm{~g} / \mathrm{cm}^{3}\right)$ is the coating effective density, and $\rho_{b}\left(\mathrm{~g} / \mathrm{cm}^{3}\right)$ is the approximation of the bulk coating density at $0 \%$ porosity. The coating mass loading, $m(\mathrm{~g} /$ $\mathrm{m}^{2}$ ), and coating thickness, $t_{c t}(\mu \mathrm{m})$, are used to define the coating density.
$P=1-\frac{\rho_{c t}}{\rho_{b}}=1-\frac{m}{t_{c t} \cdot \rho_{b}}$

\section{Electrochemical measurements}

The electrochemical performance of the half-cells was measured in a multi-channel potentiostat (BCS-805, BioLogic) at a $25^{\circ} \mathrm{C}$ room temperature. The testing protocol involved upper and lower cut-off voltages of $4.2 \mathrm{~V}$ and $2.5 \mathrm{~V}$, respectively. Formation cycle was performed at $\mathrm{C} / 20$ rate, followed by five conditioning cycles at $\mathrm{C} / 5$. Discharge $\mathrm{C}$-rate capacities were measured at $\mathrm{C} / 20, \mathrm{C} / 5, \mathrm{C} / 2,1 \mathrm{C}, 2 \mathrm{C}, 5 \mathrm{C}$ and $10 \mathrm{C}$, with all charging cycles done at $\mathrm{C} / 5$ constant current-constant voltage. Areal specific impedance (ASI), an important parameter to assess power of a cell or electrode [24], was measured using $10 \mathrm{~s}$ pulses at nine assumed $\mathrm{SoC}$ from 90 to $10 \%$, for $2 \mathrm{~s}$ pulses at $50 \% \mathrm{SoC}$, and for $30 \mathrm{~s}$ pulses at $20 \%$ SoC. These ASI parameters were based on the data required by the BatPac model for different battery applications [25]. For each test, a $1.8 \mathrm{C}$ discharge pulse was followed by a $1.2 \mathrm{C}$ charge pulse. Gravimetric capacities, $G c(\mathrm{mAh} / \mathrm{g})$, and volumetric capacities, $V c\left(\mathrm{mAh} / \mathrm{cm}^{3}\right)$, were computed from Eqs. (3) and (4), respectively, where $C_{c}$ is the cell capacity (mAh); $m_{e}$ and $m_{f}$ are the mass of the electrode and the foil (g), respectively; $A M$ is the amount of active material (wt\%); $A_{c}$ is the cell area $\left(\mathrm{cm}^{2}\right)$, and $t_{t}$ and $t_{f}$ are the total thickness and foil thickness $(\mathrm{cm})$, respectively. All the electrochemical measurements were taken on three coin cells made from the same electrode strip and used to compute the mean values and standard deviations. The electrochemical data can be found in the Online resource.

$$
\begin{aligned}
& G c=\frac{C_{c}}{\left(m_{e}-m_{f}\right)(A M)} \\
& V c=\frac{C_{c}}{A_{c}\left(t_{t}-t_{f}\right)}
\end{aligned}
$$

\section{Results and discussion}

The coded coefficients of the statistically significant terms and the $R^{2}, R_{a d j}^{2}$ and $R_{p r e d}^{2}$ for each of the responses for both electrodes are shown in Tables S1 to S4 in the Supporting Information. The $R_{a d j}^{2}$ values are plotted in Fig. 1 for visual examination of the model performances. The results are divided according to the input variables used for the statistical analysis, i.e. either the operating parameters or the cell physical properties as the factors, and are discussed in the following sections. 


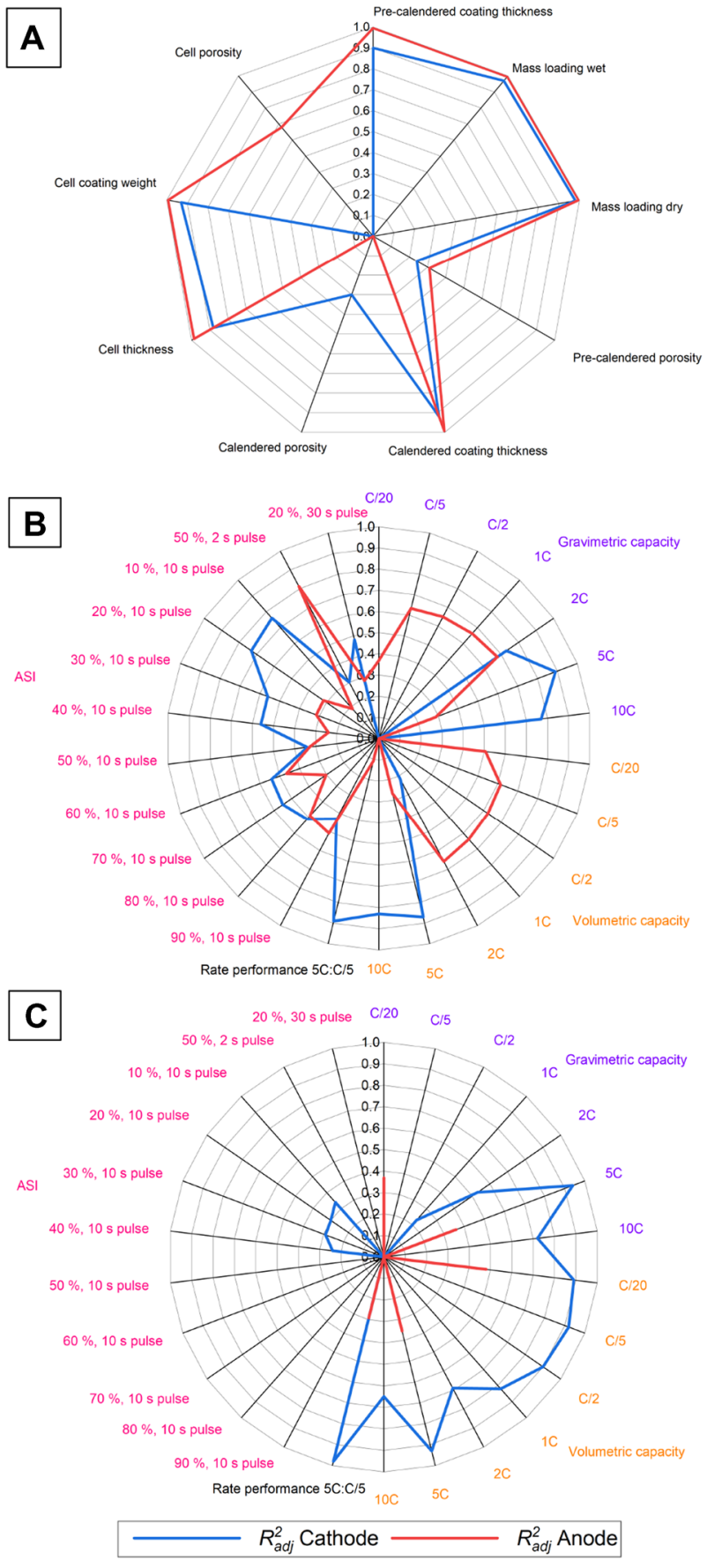

Fig. 1 Adjusted coefficient of multiple determination $\left(R_{a d j}^{2}\right)$ for the regression analysis of the following correlations: A operating variables-electrode and cell physical characteristics, B operating variables-electrochemical properties, and $\mathbf{C}$ cell physical propertieselectrochemical properties

\section{Influence of operating parameters}

\section{Physical characteristics}

The influence of comma bar gap and coating ratio, as main factors, on the cathode and cell structural properties (thickness, porosity, coating weight or mass loading) was assessed in a previous investigation [15]. It was shown that the linear models (main effects terms) can successfully predict the structural properties variations. The ICCD in this work corroborates that the previous linear models obtained are sufficient to correlate most of the cell and electrode physical properties as functions only of comma bar gap and coating ratio. The $R_{a d j}^{2}$ and $R_{\text {pred }}^{2}$ were higher than 0.80 in both cases (Fig. 1 and Table S1).

Squared terms for web speed and/or coating ratio are necessary for the pre-calendered porosity, calendered thickness and calendered porosity. However, the correlations for the porosities are rather poor $\left(R_{a d j}^{2}<0.30\right)$. In the case of the pre-calendered porosity, the model is not suitable for predictions as indicated by the negative $R_{\text {pred }}^{2}$ (Table S1) even with the squared term for the coating ratio.

Although the results reported in [15] show a strong relationship $\left(R^{2}=0.84\right)$ of pre-calendered porosity with the operating parameters and a lack of correlation of the calendered porosity with any of the parameters, the results in this study show a lower correlation for the pre-calendered porosity $\left(R^{2}=0.32\right)$ and a weak correlation for the calendered porosity $\left(R^{2}=0.37\right)$. The discrepancies may be explained by the fact that the porosities are determined from the manual measurements of the thickness at various locations of the produced electrodes and that it may be difficult to get consistent determinations. However, both studies suggest that other operating variables not considered in the experimental designs are the more influencing parameters for both types of porosities. A substantial contribution of comma bar gap, web speed and coating ratio on the calendered porosities should not be expected since research has shown that porosity is mainly affected by the calendering process $[8,9,26]$. The present results essentially demonstrate what can be inferred intuitively, that the porosities are partially influenced by the amount of material coated. The contribution of RSM is the possibility to quantify the influence of the different operating parameters through the empirical models.

For the case of anode, the selected operating variables, comma bar gap and coating ratio, are sufficient to explain the thicknesses variation at the electrode and cell level, and the mass loadings and coating weights. The models show that factor interactions are important in this case, resulting in $R_{a d j}^{2}$ and $R_{p r e d}^{2}$ values close to unity, as can be seen in Fig. 1 and Table S3. Similar to the cathode results, the porosities have the poorest correlations, but in this case not even a weak relationship between the calendered porosities and the coating parameters is found. Figure 2 shows a few examples of the good agreement between the experimental data and the modelling results for the mass 

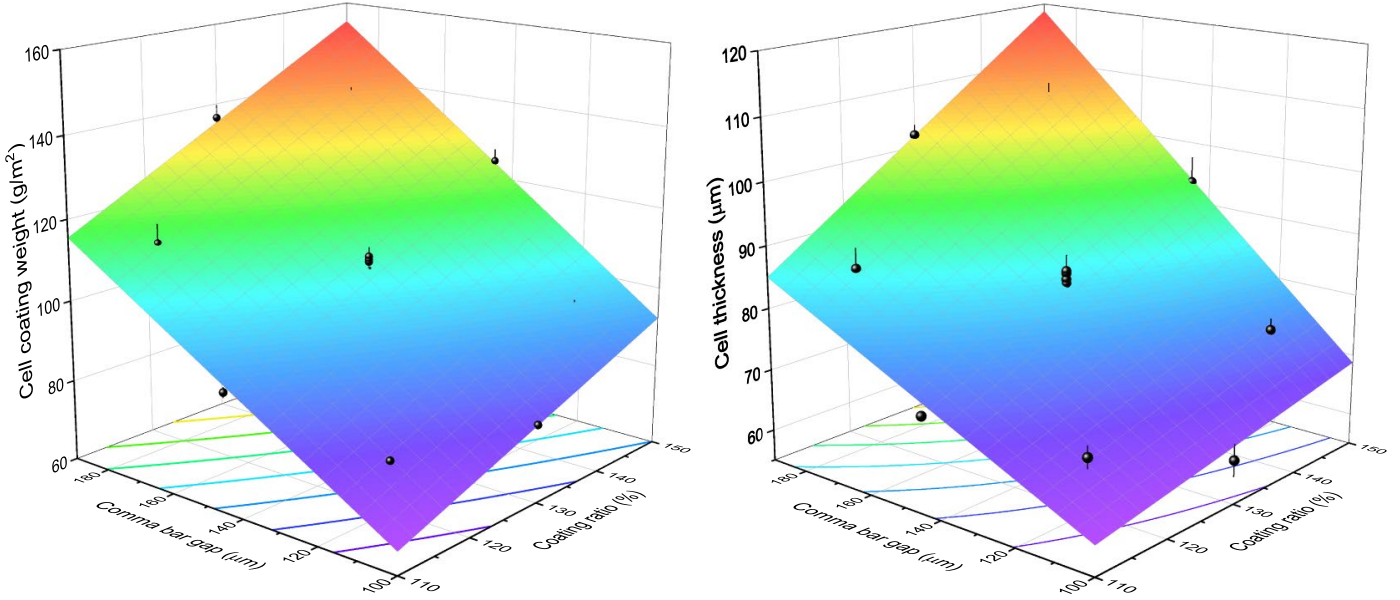

Fig. 2 Modelling surfaces for anode cell coating weight and cell thickness obtained from the coefficients in Table S3. Figures are experimental points with their standard deviations

loading dry, cell thickness and coating weight for anode as a function of operating parameters.

The obtained results agree with the multi-level model approach findings of Schmidt, et al. [26] who concluded that the uncertainties in the cathode coating step are responsible for the main uncertainties in the thickness and mass loadings. However, the study of [26] only involved variations in the wet coating thickness as the controllable parameter, and not coating operating parameters. The present work, on the other hand, establishes a direct relationship between the coating operating parameters and the electrode physical structures. The models developed in the present work are also simpler and easier to modify compared with multi-level models when changes in the parameter ranges are needed or when new variables are involved. In such cases, the ICCD can simply be extended to include the new conditions.

Because coating weights are linked to areal capacities, if the capacity of the active material is known, the settings of the coating parameters to achieve a targeted electrode areal capacity can easily be computed from the obtained models.

\section{Electrochemical performance}

As noted from Fig. 1, the studied operating parameters cannot explain all the $\mathrm{C}$-rate variations of the electrodes. The cathode gravimetric and volumetric capacities are mainly related to comma bar gap and coating ratio main effects terms only, except for the 10C volumetric capacity, for which factor interactions and squared terms are required to represent the capacities (see Table S1). The best correlations are obtained at 5C discharge capacity resulting in $R_{a d j}^{2}>0.87$. In line with previous findings [15], web speed did not have a significant influence on the capacities. Nevertheless, in contrast to [15], no correlation with any of the operating parameters was found for the $\mathrm{C} / 5$ volumetric capacity. This can be attributed to electrochemical testing variations between the two studies. Figure 3 shows the modelling results for the $5 \mathrm{C}$ and $10 \mathrm{C}$ gravimetric capacities and the $5 \mathrm{C}$ volumetric capacity as examples.

For the case of anode, all C-rates (for both the gravimetric and volumetric capacities) but $10 \mathrm{C}$, show a correlation with the operating variables (Fig. 1), albeit weak values of $R_{\text {adj }}^{2}<0.68$ are obtained (see Table S3). The $R_{\text {pred }}^{2}$ is considerably low $(<0.46)$, indicating that the models are not suitable for predictions. The results show that comma bar gap and coating ratio partially explain the observed capacities.

The cathode rate performance is also explained by the main effects of comma bar gap and coating ratio only, which is expected since the $5 \mathrm{C}$ capacities are influenced only by these two operating variables. Compared with previous findings [15], the results for cathode in this work demonstrate that the effect of air speed can be neglected from the model and still be able to get satisfactory correlations $\left(R^{2}=0.90\right.$ when air speed is omitted vs $R^{2}=0.93$ when the term is included). The anode rate performance, on the other hand, is partially explained by comma bar gap and its quadratic contribution, resulting in a considerably low $R_{a d j}^{2}(0.11)$.

As shown in Table S1, the cathode ASIs require the inclusion of main effect terms as well as factor interactions to explain the variations. For the cases at $20 \%$ SoC and $10 \%$ $\mathrm{SoC}$ at $10 \mathrm{~s}$ pulse, the quadratic term for comma bar gap is also significant. The effect of coating ratio and the comma bar gap-web speed interactions on the ASI can be appreciated, for instance, in the ASI at $20 \%$ SoC 10 s pulse plotted in Fig. 4 using the coefficients reported in Table S3. The ASI is a convex function of comma bar gap which decreases with 

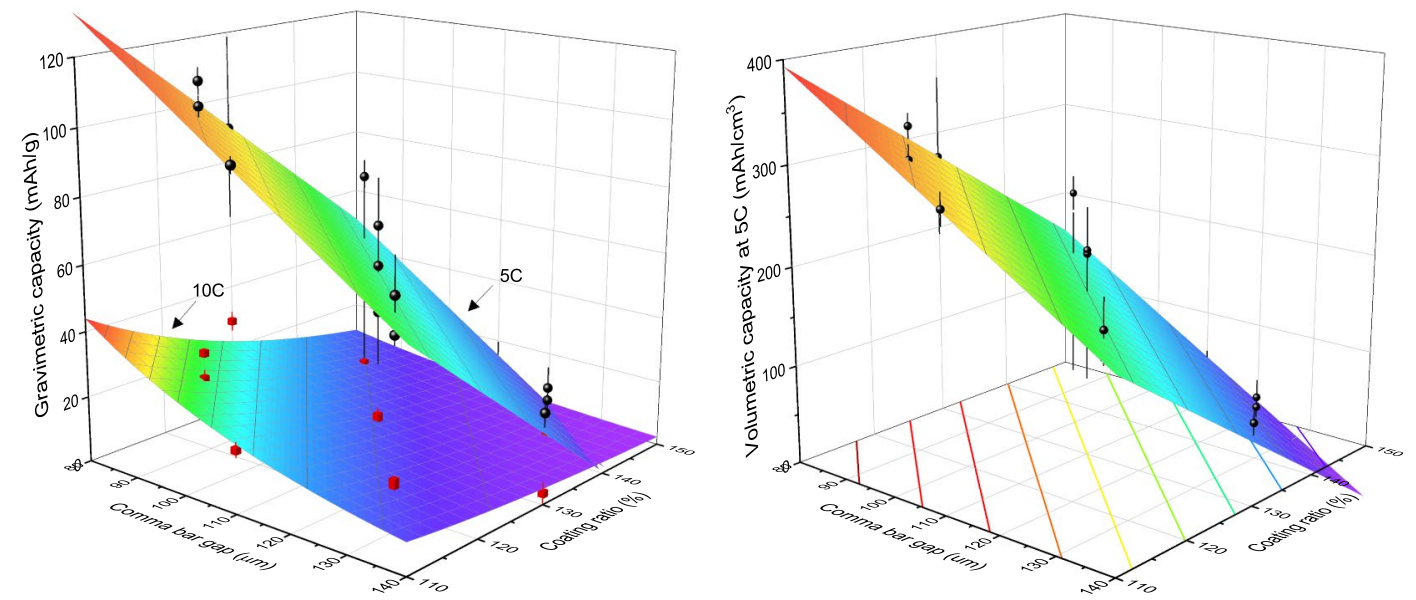

Fig. 3 Cathode gravimetric and volumetric capacity modelling results. Figures are experimental points with their standard deviations
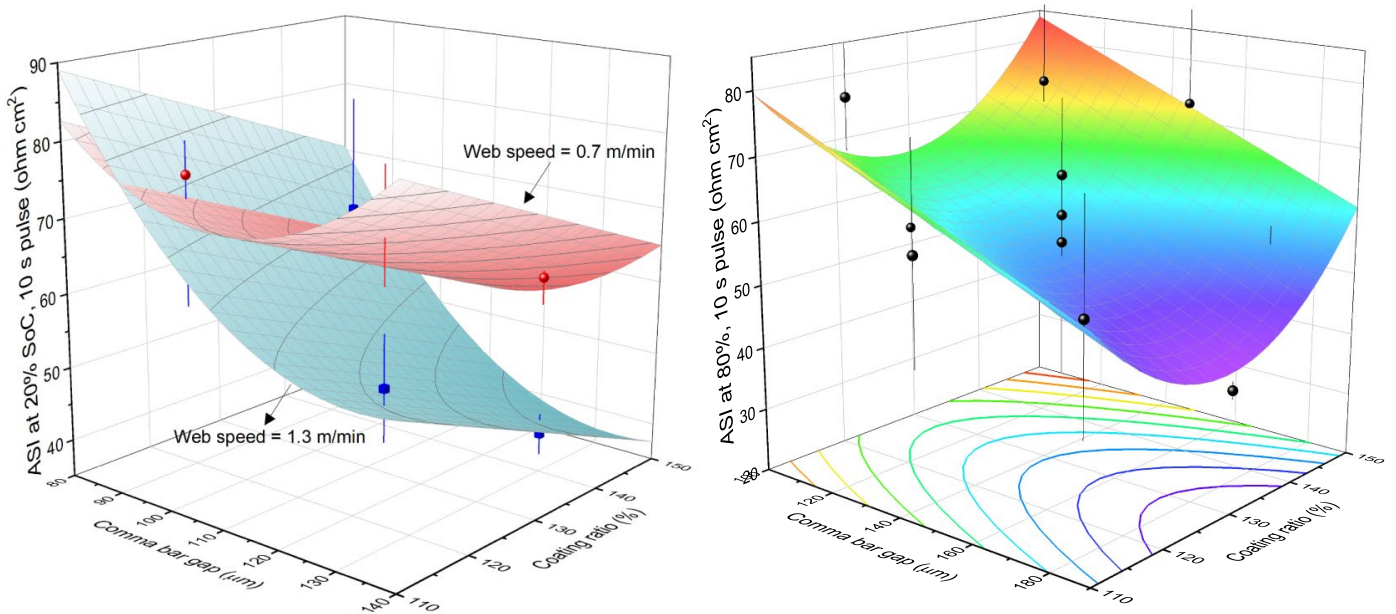

Fig. 4 Cathode ASI modelling results at $20 \%$ SoC (left) at two different web speeds, and anode ASI modelling at $80 \%$ SoC (right) as a function of comma bar gap and coating ratio only. Figures are experimental points with their standard deviations

the increase in coating ratio. Higher web speeds result, in general, in lower ASI as can be appreciated by the surfaces at $0.7 \mathrm{~m} / \mathrm{min}$ and $1.3 \mathrm{~m} / \mathrm{min}$; however, at the lowest comma bar gap and coating ratio ( $80 \mu \mathrm{m}$ and $110 \%$, respectively) the ASI is higher at $1.3 \mathrm{~m} / \mathrm{min}$ compared with the values at $0.7 \mathrm{~m} / \mathrm{min}$. The graphical representation also helps to identify optimum settings of the operating parameters that minimise the ASI. In this instance, the lowest ASI would be given by setting the web speed, the coating ratio and the comma bar gap to their highest value.

Although correlations between the ASI and the operating variables were found for all SoC, the correlations are rather poor in most cases $\left(R_{a d j}^{2}<0.56\right)$. Nevertheless, the models and the graphical representations aid in the identification of the important parameters and their settings to minimise the ASI at the different SoC.

The anode ASI, on the other hand, mainly requires the quadratic terms in addition to the main effects terms to explain the variations. Compared to cathode, the correlations are weaker (average $R_{a d j}^{2}=0.4$ ), and negative $R_{\text {pred }}^{2}$ appears in a few cases indicating a better prediction by the mean. Contrary to cathode, the anode ASI is a convex function of coating ratio and decreases as comma bar gap increases, reaching a minimum around $130 \%$ coating ratio (see Fig. 4 for the example of ASI at $80 \%$ ).

It is obvious that no optimum factors settings can be identified from the linear models. The surfaces obtained by the models containing quadratic terms show that the optimum 
settings are in fact outside the experimental region (see, for instance, Fig. 4).

\section{Influence of cell physical characteristics on electrochemical performance}

The linear relationship between cell coating weight and thickness for both electrodes can be appreciated in Figure S2. Hence, only coating weight and porosity were considered the input variables in the analysis of the electrochemical performance. The model coefficients of the statistically significant terms for cathode and anode are presented in Tables $\mathrm{S} 2$ and S4, respectively.

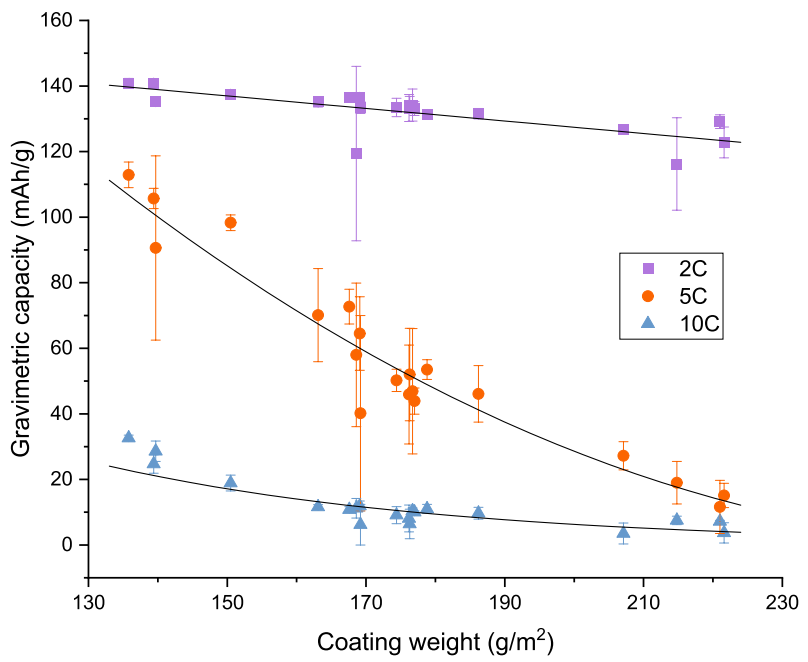

Fig. 5 Cathode gravimetric capacities as a function of coating weight for different C-rates. Lines are modelling results and figures are experimental data
For the cathode gravimetric capacities, coating weight is the only statistically significant term for the $1 \mathrm{C}$ and above rates. As shown in Fig. 5, lower coating weights result in higher capacities for all C-rates. Previous studies have also shown that improved capacities are observed at thinner (or lower coating weights) $[24,27]$ suggesting a dominated ion and electron transport process [28].

The cathode volumetric capacities, on the other hand, show a strong correlation with porosity at $1 \mathrm{C}$ and lower $\mathrm{C}$-rates $\left(R_{a d j}^{2}>0.82\right)$. At $2 \mathrm{C}$, the capacity is highly influenced by both, coating weight and porosity, and at $5 \mathrm{C}$ and $10 \mathrm{C}$ the only statistically significant term becomes coating weight. The transition from porosity as the key cell physical property for low C-rates to coating weight at high C-rates was previously reported at $1 \mathrm{C}$ [15]. However, this may be due to differences in the electrochemical testing protocols and the use of different experimental designs (ICCD vs screening). As shown in Table S2, the main effect models (i.e. the linear models) are sufficient to explain the variations of the gravimetric and volumetric capacities with either porosity or coating weight as the key property. The linear relationship between capacity and coating weight has also been described in the study of commercial lithium-ion cells [24]. Figure 6 shows the satisfactory correlations $\left(R_{a d j}^{2} \sim 0.9\right)$ of the volumetric capacities as a function of porosity or coating weight at different C-rates. As observed in Fig. 6, lower porosities or coating weights result in improved volumetric capacities. Coating weight was identified as the key characteristic explaining cathode rate performance with lower weights giving better performances.

The cathode correlations for the ASI and the cell physical characteristics were not completely satisfactory, resulting in $R_{a d j}^{2}$ values of around 0.3 , and only for four out of the eleven
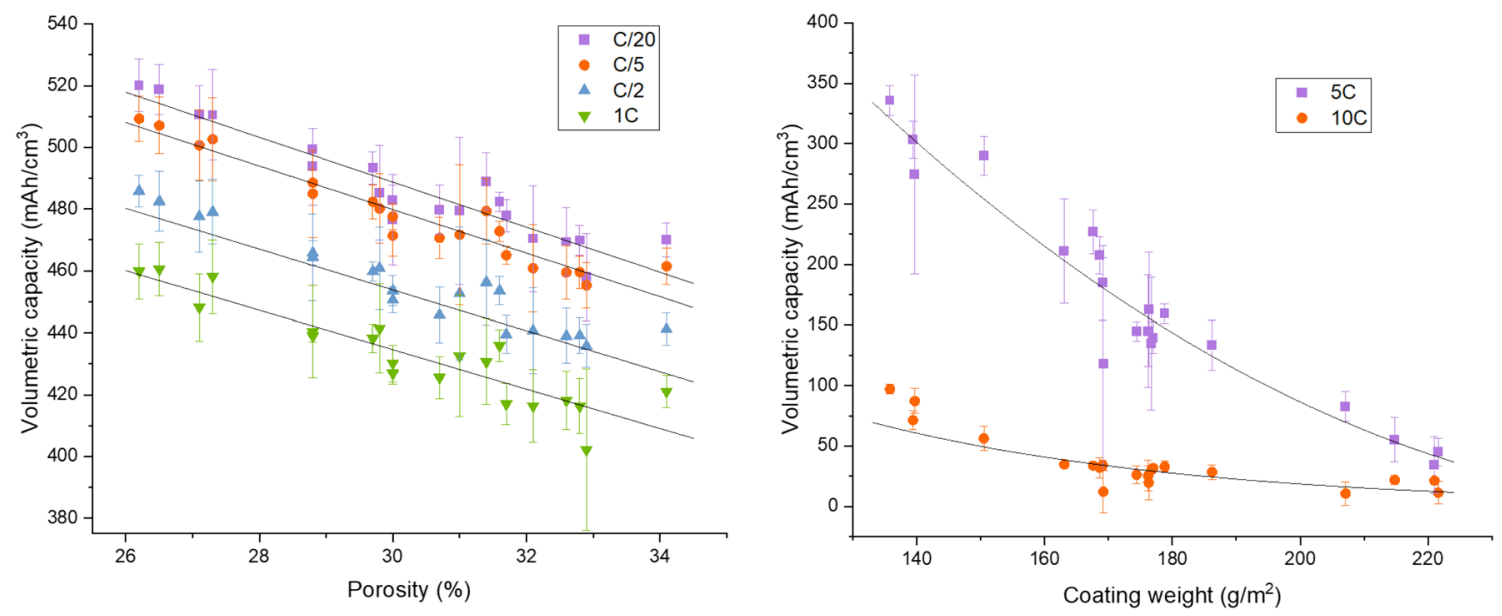

Fig. 6 Cathode volumetric capacities as a function of cell porosity (left) or coating weight (right) for different C-rates. Lines are modelling results and figures experimental data 
ASI conditions studied. The results show, nevertheless, the already reported inversely proportional relationship between ASI and coating weight $[24,29]$. The lower $R_{a d j}^{2}$ indicates that other cell physical properties, such as electrode mesostructure, microporosity and tortuosity, could have a higher contribution in explaining the ASI variation, but these were not considered in the present work. Such properties are likely being affected by web speed since ASI was better correlated by the operating variables as the input variables.

For the case of anode, the $\mathrm{C} / 20$ and $5 \mathrm{C}$ gravimetric and volumetric capacities and rate performance were the only electrochemical properties with a correlation with the cell physical characteristics, but with rather poor correlations $\left(R_{a d j}^{2}<0.48\right)$. Because good correlations were observed for the operating parameters as factors, there seems to be a property not considered in the present study but affected by the operating parameters the actual explanatory physical property.

\section{Optimisation}

The multiple cell performance indicators (responses) involved in the study do not allow for a straightforward determination of the general optimum. Conflicting optimum conditions may be encountered since the best conditions for one response may not be the best for another. This is exemplified in the case of the capacities and the ASI. As described in Sect. 3.2, lower coating weights result in higher gravimetric and volumetric capacities, but at the same time it increases the ASI, which is undesirable. The optimum coating weight would be the one that maximises the capacity but at the lowest ASI. However, since the current studied physical properties cannot capture all the variations in the ASI, a better approach in this case would be to perform the optimisation in terms of the operating parameters. The conflicting criteria are still present because certain values of the comma bar gap and coating ratio will result in higher capacities but simultaneously in higher ASI (Sect. 3.1.2). Moreover, web speed also affects the ASI as described in Sect. 3.1.2. To give a specific example, a nonlinear optimisation problem is stated in Eq. (5), where the goal is to determine the optimum settings of comma bar gap $\left(x_{1}\right)$, web speed $\left(x_{2}\right)$ and coating ratio $\left(x_{3}\right)$ that will maximise the cathode $5 \mathrm{C}$ gravimetric capacity $\left(y_{1}\right)$ but at the lowest ASI $20 \%$ SoC 10 s pulse $\left(y_{2}\right)$. Equation (5) also considers the $5 \mathrm{C}$ volumetric capacity $\left(y_{3}\right)$ as an additional response involved the optimisation.

$\max y_{1}$

subject to $\left\{\begin{array}{c}30 \leq y_{2} \leq 60 \\ y_{3} \leq 400 \\ 80 \leq x_{1} \leq 140 \\ 0.5 \leq x_{2} \leq 1.5 \\ 110 \leq x_{3} \leq 150\end{array}\right.$
Equation (5) was solved by the CONOPT solver in GAMS. The optimum values of the capacities and the ASI are as follows: $y_{1}=99.6 \mathrm{mAh} / \mathrm{g}, y_{2}=60.0 \Omega \mathrm{cm}^{2}$ and $y_{3}=295.1 \mathrm{mAh} / \mathrm{cm}^{3}$, at the following settings: comma bar gap $=108 \mu \mathrm{m}$, web speed $=1.5 \mathrm{~m} / \mathrm{s}$ and coating ratio $=110 \%$. Substitution of the optimum parameters on the corresponding models gives the values of other properties, for instance, the electrode thickness.

\section{Conclusions}

The present work contributes to a better understanding of the coating operating parameter-electrode physical properties-cell electrochemical performance relationship of both electrodes. Comma bar gap, web speed and coating ratio are demonstrated to be the key parameters in the cathode manufacture, whereas comma bar gap and coating ratio for anode. These parameters can capture as much as $99 \%$ of the variation of the thicknesses, mass loadings and coating weights. On the other hand, the studied process parameters cannot explain the porosities variation, meaning that other manufacturing steps (e.g. calendering) have a more important effect. Electrochemical performance also cannot be completely explained by the coating parameters. In general, more correlations for the capacities are found for anode compared with cathode, implying that although the cathode performance is influenced by the coating process, other manufacturing steps (e.g. mixing or calendaring) may have a higher influence.

Modelling of the ASI was more complex, as shown by the parameter interactions and squared terms in the models. Although, on average, more than $60 \%$ of the variation can be explained by the developed models, the results suggest that variables from other manufacturing steps also contribute to the ASI performance.

Regarding the physical properties-electrochemical performance relationship, coating weight is the dominant property influencing most of the capacity performance for cathode, although porosity is the main property at low volumetric C-rates. For anode, on the other hand, no satisfactory correlations were found between the physical properties and electrochemical performance. The ASI, for both electrodes, cannot be explained by cell coating weight and porosity. Other properties such as electrode mesostructure, microporosity and tortuosity should be studied as potential explanatory variables.

The obtained mathematical models can be used to (i) establish machine setting to achieve a targeted vale of the electrode properties, (ii) for cell design by determining the cell coating weights or porosities to attain targeted capacities and rate performance, and (iii) for multi-variable optimisation to satisfy several performance criteria. 
Supplementary Information The online version contains supplementary material available at https://doi.org/10.1007/s40095-022-00481-w.

Acknowledgements This research was undertaken through the NEXTRODE Project, funded by the Faraday Institution (Grant Number: FIRG015).

\section{Declarations}

Conflict of interest The authors declare that they have no conflict of interest.

Open Access This article is licensed under a Creative Commons Attribution 4.0 International License, which permits use, sharing, adaptation, distribution and reproduction in any medium or format, as long as you give appropriate credit to the original author(s) and the source, provide a link to the Creative Commons licence, and indicate if changes were made. The images or other third party material in this article are included in the article's Creative Commons licence, unless indicated otherwise in a credit line to the material. If material is not included in the article's Creative Commons licence and your intended use is not permitted by statutory regulation or exceeds the permitted use, you will need to obtain permission directly from the copyright holder. To view a copy of this licence, visit http://creativecommons.org/licenses/by/4.0/.

\section{References}

1. Chen, W., Liang, J., Yang, Z., Li, G.: A review of lithium-ion battery for electric vehicle applications and beyond. Energy Procedia 158, 4363-4368 (2019). https://doi.org/10.1016/j.egypro.2019.01. 783

2. Wang, Q.-K., Shen, J.-N., He, Y.-J., Ma, Z.-F.: Design and management of lithium-ion batteries: A perspective from modeling, simulation, and optimization. Chin. Phys. B 29(6), 068201 (2020). https://doi.org/10.1088/1674-1056/ab90f8

3. Foley, B., Degirmenci, K., Yigitcanlar, T.: Factors affecting electric vehicle uptake: insights from a descriptive analysis in Australia. Urban Sci. 4(4), 57 (2020)

4. Sanguesa, J.A., Torres-Sanz, V., Garrido, P., Martinez, F.J., Marquez-Barja, J.M.: A review on electric vehicles: technologies and challenges. Smart Cities 4(1), 372-404 (2021)

5. Meyer, O., Weihs, C., Mähr, S., Tran, H.-Y., Kirchhof, M., Schnackenberg, S., Neuhaus-Stern, J., Rößler, S., Braunwarth, W.: Development and implementation of statistical methods for quality optimization in the large-format lithium-ion cells production. Energy Technol. 8(2), 1900244 (2020). https://doi.org/10. 1002/ente.201900244

6. Turetskyy, A., Thiede, S., Thomitzek, M., von Drachenfels, N., Pape, T., Herrmann, C.: Toward data-driven applications in lithium-ion battery cell manufacturing. Energy Technol. 8(2), 1900136-1900136 (2020). https://doi.org/10.1002/ente.20190 0136

7. Schönemann, M., Bockholt, H., Thiede, S., Kwade, A., Herrmann, C.: Multiscale simulation approach for production systems: application to the production of lithium-ion battery cells. Int. J. Adv. Manuf. Technol. 102(5-8), 1373-1390 (2019). https://doi.org/10. 1007/s00170-018-3054-y

8. Primo, E.N., Chouchane, M., Touzin, M., Vazquez, P., Franco, A.A.: Understanding the calendering processability of $\mathrm{Li}(\mathrm{Ni0}$.33Mn0.33Co0.33)O2-based cathodes. J. Power Sources
488, 229361 (2021). https://doi.org/10.1016/j.jpowsour.2020. 229361

9. Kwade, A., Haselrieder, W., Leithoff, R., Modlinger, A., Dietrich, F., Droeder, K.: Current status and challenges for automotive battery production technologies. Nat. Energy 3(4), 290-300 (2018). https://doi.org/10.1038/s41560-018-0130-3

10. Wang, M., Dang, D., Meyer, A., Arsenault, R., Cheng, Y.-T.: Effects of the mixing sequence on making lithium ion battery electrodes. J. Electrochem. Soc. 167(10), 100518 (2020). https:// doi.org/10.1149/1945-7111/ab95c6

11. Konda, K., Moodakare, S.B., Kumar, P.L., Battabyal, M., Seth, J.R., Juvekar, V.A., Gopalan, R.: Comprehensive effort on electrode slurry preparation for better electrochemical performance of LiFePO4 battery. J. Power Sources 480, 228837 (2020). https:// doi.org/10.1016/j.jpowsour.2020.228837

12. Hawley, W.B., Li, J.: Beneficial rheological properties of lithiumion battery cathode slurries from elevated mixing and coating temperatures. J. Energy Storage 26, 100994 (2019). https://doi. org/10.1016/j.est.2019.100994

13. Meyer, C., Weyhe, M., Haselrieder, W., Kwade, A.: Heated calendering of cathodes for lithium-ion batteries with varied carbon black and binder contents. Energy Technol. 8(2), 1900175 (2020). https://doi.org/10.1002/ente.201900175

14. Westphal, B.G., Mainusch, N., Meyer, C., Haselrieder, W., Indrikova, M., Titscher, P., Bockholt, H., Viöl, W., Kwade, A.: Influence of high intensive dry mixing and calendering on relative electrode resistivity determined via an advanced two point approach. J. Energy Storage 11, 76-85 (2017). https://doi.org/10.1016/j.est. 2017.02.001

15. Román-Ramírez, L.A., Apachitei, G., Faraji Niri, M., Lain, M., Widanage, D., Marco, J.: Understanding the effect of coatingdrying operating variables on electrode physical and electrochemical properties of lithium-ion batteries. J. Power Sources (2021). https://doi.org/10.1016/j.jpowsour.2021.230689

16. Duquesnoy, M., Boyano, I., Ganborena, L., Cereijo, P., Ayerbe, E., Franco, A.A.: Machine learning-based assessment of the impact of the manufacturing process on battery electrode heterogeneity. Energy and AI 5, 100090 (2021). https://doi.org/10.1016/j.egyai. 2021.100090

17. Keppeler, M., Tran, H.-Y., Braunwarth, W.: The role of pilot lines in bridging the gap between fundamental research and industrial production for lithium-ion battery cells relevant to sustainable electromobility: a review. Energy Technol. 9(8), 2100132 (2021). https://doi.org/10.1002/ente.202100132

18. Niri, M.F., Liu, K., Apachitei, G., Román-Ramírez, L.A.A., Lain, M., Widanage, D., Marco, J.: Quantifying key factors for optimised manufacturing of Li-ion battery anode and cathode via artificial intelligence. Energy and AI 7, 100129 (2022). https:// doi.org/10.1016/j.egyai.2021.100129

19. Turetskyy, A., Wessel, J., Herrmann, C., Thiede, S.: Battery production design using multi-output machine learning models. Energy Storage Materials 38, 93-112 (2021). https://doi.org/10. 1016/j.ensm.2021.03.002

20. Myers, R.H., Montgomery, D.C., Anderson-Cook, C.M.: Response surface methodology: process and product optimization using designed experiments. In: Balding, D.J., Cressie, N.A.C., Fitzmaurice, G.M., Givens, G.H., Goldstein, H., Molenberghs, G., Scott, D.W., Smith, A.F.M., Tsay, R.S., Weisberg, S. (eds.) Wiley series in probability and statistics, p. 865. Wiley, New Jersey (2016)

21. Román-Ramírez, L.A., Apachitei, G., Faraji Niri, M., Lain, M., Widanage, D., Marco, J.: Experimental data of cathodes manufactured in a convective dryer at the pilot-plant scale, and charge and discharge capacities of half-coin lithium-ion cells. Data Brief 40, 107720 (2022). https://doi.org/10.1016/j.dib.2021.107720 
22. Román-Ramírez, L.A., Marco, J.: Design of experiments applied to lithium-ion batteries: A literature review. Submitted, (2021).

23. Cox, D.R., Reid, N.: The theory of the design of experiments. CRC Press, USA (2000)

24. Lain, M.J., Kendrick, E.: Understanding the limitations of lithium ion batteries at high rates. J. Power Sources 493, 229690 (2021). https://doi.org/10.1016/j.jpowsour.2021.229690

25. Argonne National Laboratory: Modeling the performance and cost of lithium-ion batteries for electric-drive vehicles. Department of Energy, U.S. (2012).

26. Schmidt, O., Thomitzek, M., Röder, F., Thiede, S., Herrmann, C., Krewer, U.: Modeling the impact of manufacturing uncertainties on lithium-ion batteries. J. Electrochem. Soc. 167(6), 060501 (2020). https://doi.org/10.1149/1945-7111/ab798a

27. Tian, R., Park, S.-H., King, P.J., Cunningham, G., Coelho, J., Nicolosi, V., Coleman, J.N.: Quantifying the factors limiting rate performance in battery electrodes. Nat. Commun. 10(1), 1-11 (2019). https://doi.org/10.1038/s41467-019-09792-9

28. Saraka, R.M., Morelly, S.L., Tang, M.H., Alvarez, N.J.: Correlating processing conditions to short- and long-range order in coating and drying lithium-ion batteries. ACS Appl. Energy Mater. 3(12), 11681-11689 (2020). https://doi.org/10.1021/acsaem.0c01305

29. Gallagher, K.G., Nelson, P.A., Dees, D.W.: Simplified calculation of the area specific impedance for battery design. J. Power Sources 196(4), 2289-2297 (2011). https://doi.org/10.1016/j.jpowsour. 2010.10 .020

Publisher's Note Springer Nature remains neutral with regard to jurisdictional claims in published maps and institutional affiliations. 